\title{
Etnografia e aprendizagem na prática: explorando caminhos a partir do futebol no Brasil
}

\author{
Ana Maria R. Gomes' \\ Eliene Lopes Faria'
}

\section{Resumo}

0 artigo propõe apresentar reflexões e questões construídas na condução de pesquisas a respeito do tema da aprendizagem em contextos de práticas sociais diversificadas. A orientação comum que permitiu o confronto entre os diferentes trabalhos e contextos empíricos foi construída a partir da abordagem da aprendizagem situada de Jean Lave (1991, 2011), em diálogo com autores como Gregory Bateson (1972) e Tim Ingold (2000). Os contextos investigados caracterizam-se pela singularidade em relação a temas próprios da sociedade brasileira, tais como o futebol, as religiões afro-brasileiras, práticas tradicionais indígenas, dentre outras. Em todas as investigações, o eixo condutor foi a prática em suas diversas configurações - o que quase sempre inclui a escola, que é, no entanto, ressituada a partir do ponto de vista da prática focalizada na investigação. Alguns aspectos recorrentes indicaram a possibilidade de se pensar na aprendizagem da cultura como tema de pesquisa que atravessa fronteiras disciplinares e que permite revelar facetas inusitadas de práticas que marcam a paisagem do Brasil contemporâneo. Como recorte, o artigo discute as reflexões de caráter conceitual-metodológico que as investigações permitiram realizar a partir de um duplo movimento: focalizando aspectos relevantes que emergiram nas investigações (sobretudo a partir do caso emblemático do futebol, cuja aprendizagem é amplamente difundida no Brasil); e produzindo reflexões acerca da prática etnográfica, ao recolocar a etnografia como fundamento para a realização de tal empreitada.

\section{Palavras-chave}

Aprendizagem situada - Aprendizagem na prática - Etnografia Antropologia e educação.

I- Universidade Federal de Minas Gerais (UFMG), Belo Horizonte, MG, Brasil.

Contatos: anarabelogomes.bhz@gmail.com; elienelopesfaria@gmail.com 


\title{
Ethnography and learning in practice: exploring pathways from the case of soccer in Brazil
}

Ana Maria R. Gomes'

Eliene Lopes Faria'

\begin{abstract}
This study presents reflections developed while conducting research on learning in different social practice settings. The common framework that allowed the dialogue between different studies and empirical contexts has drawn from Jean Lave's learning approach $(1991 ; 2011)$ in dialogue with authors such as Gregory Bateson (1972) and Tim Ingold (2000). The practices investigated are marked by their singularity regarding fields that characterize the Brazilian society, such as soccer, Afro-Brazilian religions, and indigenous traditional practices. All investigations focused on practices in their diverse configurations in different settings, which nearly always includes the school, which is resituated from the viewpoint of the practice under research. Some recurring aspects suggested that cultural learning may be considered a research subject that crosses disciplinary boundaries and reveals unexpected facets of practices that mark the contemporary scenario of Brazil. The article specifically discusses conceptual and methodological reflections in a double movement: focusing on relevant and common aspects that emerged in the analysis, especially that of the emblematic case of soccer, the learning of which is widespread in Brazil; and repositioning ethnography as a basis for conducting such task, thus producing reflections on ethnographic practice.
\end{abstract}

\section{Keywords}

Situated learning - Learning in practice - Ethnography Anthropology and education.

I- Universidade Federal de Minas Gerais (UFMG), Belo Horizonte, MG, Brasil.

Contatos: anarabelogomes.bhz@gmail.com elienelopesfaria@gmail.com 
Neste artigo, pretendemos revisar as orientações que foram se configurando ao longo dos últimos dez anos em trabalhos etnográficos a respeito de temáticas que se situam na interface entre antropologia e a educação, ou seja, cuja pertinência se coloca para ambos os campos, ainda que não sejam muito contempladas na atual produção - como é o tema da aprendizagem da cultura (GOMES, 2006, 2014).

As provocações iniciais que nos levaram a delinear essa direção de nossos trabalhos nasceram de algumas situações investigadas que podem ser emblematicamente referidas por meio de dois exemplos. 0 primeiro deles foi a tentativa de descrever o processo de aprendizagem de uma prática presente entre os Xakriabá, em uma aldeia indígena do norte de Minas Gerais, na qual especialmente as mulheres reproduzem entre si a habilidade de construir casas de barro através de um singular processo construtivo (PEREIRA, 2003).

$\mathrm{Na}$ ocasião, o desafio era ir além das afırmações, muito frequentes quando se trata de abordar práticas identificadas como tradicionais, de que as pessoas aprendem fazendo. Fomos surpreendidas, no curso do trabalho de campo, por uma das mulheres construtoras que afirmou que "aprendeu vadiando". 0 termo vadiar, na linguagem local, significa "fazer nada”, e é usado frequentemente para se referir ao que as crianças fazem ao circularem pelo território no entorno da aldeia: "estão por aí, vadiando". No que diz respeito à etnografia, a expressão sugeria que se tratava de algo disperso nas atividades cotidianas, algo que não era focalizado e topicalizado como tendo uma dinâmica em si, que se apresentasse explicitamente para as próprias pessoas envolvidas.

Tal quadro solicitava uma inserção em campo prolongada, de forma a verificar como, em um percurso dilatado no tempo e no espaço, e cobrindo a experiência de diferentes gerações, poderiam ser captadas as ações e interações que teriam permitido esse "aprender vadiando", ou seja, aprender enquanto "não se faz nada", ou pelo menos nada que seja considerado digno de ser referido do ponto de vista de quem já tem domínio daquela atividade ou técnica uma vez que são essas as pessoas normalmente interpeladas.

Se esse pode ser considerado o quadro de uma etnografia clássica, é curioso observar, no entanto, que o tema da aprendizagem dos elementos culturais assim diluídos na vida cotidiana não se faz presente na maioria das monografias; ou melhor, se faz presente assim: de forma diluída e não topicalizada. Por essa razão, requer, portanto, para que sejam identificadas descrições em meio a trabalhos dedicados a outras temáticas, um esforço de busca lento e multidirecionado, pois embora o tema seja onipresente, na maioria dos trabalhos não é indexado, nem discutido/analisado como tal ${ }^{1}$.

Com o avanço na proposição de uma antropologia da criança no Brasil (LOPES DA SILVA; MACEDO; NUNES, 2002; COHN, 2000; TASSINARI, 2007, 2009), o tema do aprendizado aparece topicalizado, começando a ser contemplado a partir desse olhar - da criança que aparentemente faz nada, ou brinca, mas aprende as práticas que caracterizam a vida de seu grupo social, de sua comunidade ${ }^{2}$. De modo especial, esse tema emergiu nas investigações acerca das crianças indígenas e permitiu que se constituísse no grupo uma importante interface com as propostas de A\&tE inspiradas na experiência das escolas indígenas, como sugerido por Lopes da Silva (2001). Para se abordar os processos de aprendizagem nas sociedades indígenas, temas centrais como o da construção da pessoa e o da corporalidade como dimensão decisiva desses processos trouxeram essa perspectiva de uma forma original para se pensar a temática mais ampla.

1- Ver, a título de exemplo, Learning religion (BERLINER, 2007); Making knowledge (MARCHAND, 2010); e duas monografias nas quais o etnógrafo se tornou praticante: Learning capoeira (DOWNEY, 2005); Aprendiz de boxe (WACQUANT, 2002).

2- Vamos nos limitar aqui a referir as contribuições da antropologia da criança - e em especial da criança indígena - sem maiores referências aos estudos da infância em geral, e à discussão específica que se faz acerca da pesquisa com crianças na sociologia e na psicologia. 
No entanto, cabe afirmar aqui que a temática da aprendizagem da cultura não se circunscreve ao universo da infância. Se, por um lado, tem sido muito importante levar em conta as contribuições desse campo específico, foi preciso criar um enquadramento que não se identificasse exclusivamente com esse processo de formação das jovens gerações.

0 segundo exemplo - que veio a se tornar um caso emblemático para o tipo de enquadramento que foi se constituindo - é o da aprendizagem do futebol como fenômeno muito presente na sociedade brasileira, o qual foi investigado, em seu período inicial, junto a meninos de um bairro da periferia de Belo Horizonte (FARIA, 2008). 0 tema surgiu a partir de uma investigação anterior acerca do esporte nas aulas de educação física em escolas da rede pública de Belo Horizonte (MG), na qual as atividades de ensino-aprendizagem de diferentes modalidades de esporte foram observadas e descritas, sendo que uma singularidade muito forte se destacou em relação ao que seria o ensino-aprendizagem do futebol (FARIA, 2001). Enquanto todas as demais práticas esportivas eram apresentadas dentro do padrão recorrente de ação em que ao professor cabe o lugar de propositor, orientador e regulador das ações, no caso do futebol os alunos se impunham de uma forma tão incisa que não era passível de ser confrontada pelos professores: estes deviam se afastar e não interferir na organização e na realização do jogo, que era todo conduzido pelos alunos. Ao final do ano, como celebração, havia a partida de futebol entre alunos e professores, com vitória sempre para os primeiros.

Como afırma Peirano (1992), a força do relato etnográfico está em dizer algo para além do que pretendeu o etnógrafo, algo que os sujeitos com os quais ele interagiu e junto aos quais ele realizou sua pesquisa teriam a dizer, e que o relato revela, muitas vezes à revelia do próprio etnógrafo. Dizer isso é importante, pois, o objetivo da investigação de Faria (2001) era descrever/analisar a multiplicidade de usos e significados dos esportes na escola e a negociação permanente em torno deles. Mas, foi a insistência/irreverência do futebol no cotidiano escolar, bem como a sua singular forma de produção que permitiu que o debate em torno dessa prática fosse recolocado. Para além da dinamicidade e ambiguidade das práticas esportivas nas escolas pesquisadas, o trabalho de campo desvelou um fato que, a princípio, nada trazia de novo: o futebol acontece cotidianamente na escola de maneira independente das práticas de ensino (práticas denominadas no âmbito da educação física como aula rola bola); o futebol (seus praticantes) não se submete às práticas pedagógicas e/ou imperativos escolares. Conforme reiterou um professor de educação física:

[...] o pouco que a gente tenta ensinar, não é aceito não. [...] Os meninos aqui na escola... eles têm muito isso. Eles não querem aprender [futebol], eles querem saber (FARIA, 2001, p. 143).

Chamou-nos a atenção essa situação singular - em um contexto marcado por regulações institucionais, onde podemos identificar a força da "forma escolar" em ação como modelo de socialização (VINCENT; LAHIRE; THIN, 2000) - de uma prática cultural que pudesse reverter a ordem instituída e impor uma lógica outra de ação.

0 desdobramento do debate em torno dessa imposição do futebol sobre a organização escolar provocou o deslocamento da pesquisa com a instalação de uma nova pergunta: Se no futebol que acontece na escola as práticas de ensino são quase inexistentes, como é possível aprender? Onde e como é possível que a prática do futebol aconteça? Essa crucial mudança de foco culminou na formulação de indagações importantes a respeito da produção cotidiana do futebol no Brasil. Tal problematização, dada a inserção cultural dessa prática no país, no limite, poderia servir como metáfora para a compreensão de como a cultura é aprendida. 
Foi esse o motivo inicial que suscitou a possibilidade de se realizar uma pesquisa a respeito da aprendizagem do futebol, considerando-o como uma prática que tem características específicas na sociedade brasileira. Interessava-nos compreender como essa prática se organizava e de que forma ela poderia ser tão fortemente presente a ponto de permitir que pessoas que não a dominam como os meninos em idade escolar - tenham tão claras convicções acerca do modo como ela poderia ser aprendida. Ou seja, não saber jogar futebol não era obstáculo para que os alunos fossem plenamente convictos a respeito do modo como eles poderiam aprender a jogar. $\mathrm{Ou}$ ainda, podemos afırmar que convicções acerca da aprendizagem da prática do futebol eram disponíveis e de público domínio, mais ainda que o próprio domínio da prática futebolística.

Com o caso do futebol, configurou-se a ideia de que a etnografia deveria focalizar a prática cultural investigada em seus vários contextos de produção. 0 foco deixava de ser cada contexto em sua lógica - como quando se tratava dos temas escolares e se projetava a definição dos demais como não escolares - e passava a ser a produção da prática e dos praticantes.

Nesse percurso, as demarcações inauguradas por Gregory Bateson, nos anos 1970, quanto à conceituação e descrição dos processos de aprendizagem em uma abordagem cibernética; e o trabalho de Jean Lave, nos anos 1990, quanto ao modelo do apprenticeship e da aprendizagem situada foram de fundamental importância para gerar o enquadramento que veio a se constituir para as propostas de investigação a respeito do que estamos chamando de aprender a cultura. As contribuições de Tim Ingold (2000) somaram-se a esse quadro, especialmente no que se refere à noção de habilidade (skill). Colocava-se a necessidade de realizar uma etnografia que fosse orientada pela prática em questão, que se organizasse em campo e na própria monografia a partir do movimento dessa prática em suas diferentes articulações.
É importante ressaltar que trabalhos recentes têm se debruçado sobre a produção das etnografias na pesquisa em educação no Brasil. Vamos nos valer de diversos aspectos indicados nesses trabalhos, sem, contudo, ter uma mirada intencionada à revisão do tema. Vamos nos limitar a trazer para a cena investigações e autores que, de alguma forma, contribuíram para o delineamento da orientação que foi se configurando em torno do tema da aprendizagem da cultura, e aos desdobramentos que ele produziu em pesquisas que, além das já referidas, abarcaram temáticas como a aprendizagem em um terreiro de umbanda (BERGO, 2011) e a aprendizagem dos meninos caçadores Xakriabá no território indígena de seu povo (SILVA, 2011). 0 que acomuna esses trabalhos foi a intenção compartilhada de se abordar o tema da aprendizagem e a opção pela prática da etnografia.

As investigações que inicialmente trouxeram a etnografia para a pesquisa em educação, no caso do meio urbano no Brasil, tiveram seu desenvolvimento marcado pela própria antropologia urbana, em meados dos anos 1980 e seguindo pelos anos 1990. A antropologia urbana havia, então, produzido um enquadramento para a prática etnográfica que se confrontava com as diferentes formas de inserção no campo, com as formulações que se tornaram muito conhecidas de G. Velho e R. DaMatta a respeito da posição do etnógrafo quando o contexto de sua investigação está mais próximo e lhe é parcialmente conhecido, ou quanto menos familiar. Por meio da oposição entre familiar X exótico, os autores chamam a atenção para o tipo de deslocamento do olhar, necessário para que a pesquisa possa avançar. Nesse tipo de investigação, o pesquisador precisa tomar consciência de seu desconhecimento a respeito de situações e pessoas com quem vive (nesse sentido, familiares) ou tomar consciência de seu mundo e de seu modo de mover-se nele.

Com Wagner (2010), podemos afirmar que, independentemente do tipo de inserção, de uma coisa nenhum etnógrafo escapa: em 
campo ele terá de se haver com as suas próprias concepções e conceitos. A incursão etnográfica exige, portanto, assumir a necessidade de rever/identificar as demarcações que envolvem historicamente esse ofício/exercício da etnografia e, também, as do próprio pesquisador. Segundo Wagner (2010, p. 46), desenvolver o senso de uma "objetividade relativa" implica assumir que as "culturas" em campo têm ambas capacidades igualmente criativas (WAGNER, 2010, p. 46).

Não seria aqui possível abordar todas as contribuições de diferentes autores e linhas de pesquisa para uma revisão que fizesse justiça às muitas possibilidades e controvérsias presentes na produção de etnografias na pesquisa em educação no Brasil, ou que a ela possam interessar, e com as quais interagimos de forma ainda que indireta (ANDRÉ, 1995; DAUSTER, 1996; GREEN; DIXON; ZAHARLICK, 2005; BUENO, 2007; OLIVEIRA, 2013) ${ }^{3}$. No entanto, vale ressaltar que a proposta que vem sendo construída em muito tem possibilitado revisitar diferentes autores e temas de investigação.

Da antropologia e da educação americana retiramos a importante indicação de que é necessário conduzir investigações nas comunidades e nas escolas (BRICE HEATH, 1983), com a devida atenção para a diferença entre esses contextos, assim como para a não linearidade entre o que se pode inferir de um para o outro. A sensibilidade para as diferentes orientações culturais presentes em um mesmo contexto escolar (ERICKSON; MOHATT, 1982), e a necessidade de se dialogar com essas diferentes lógicas é outra orientação de fundamental importância. Com Mehan (1979), a escola é tomada como um contexto de práticas específicas, as quais precisam também ser aprendidas pelos estudantes. Esse foco é, de certa forma, também o que orienta a proposta da etnografia da escola na Sociologia da Educação britânica (WOODS, 1986), na qual, com uma abordagem fundada no interacionismo simbólico, os estudos concentram-se nas constrições que a vida na

3- Para uma revisão realizada no contexto italiano, ver Gobbo; Gomes, 2003. instituição escolar produzia nos diferentes sujeitos que dela participavam - professores e alunos - com as descrições de suas ações como imbuídas, ou impelidas em responder, resistir ou mesmo sobreviver a essas constrições. 0 trabalho pioneiro de Willis (1977) remete-nos às questões identitárias - sempre envolvidas nas dinâmicas escolares e sociais como um todo.

$\mathrm{Na}$ vertente sul-americana, temos a contribuição dos trabalhos de Rockwell (1995, 1999), que nos chama atenção para a dimensão cotidiana das práticas escolares, sempre marcadas por processos de dominação e apropriação. A historicidade dos contextos de interação, e suas possíveis mudanças, a atenção com as relações de poder e o foco privilegiado nas dinâmicas da vida cotidiana - ainda que em setting institucional (cotidianidade essa que é muito focalizada quando se trata da vida em comunidade e nas assim chamadas situações de aprendizagem informal), são elementos que nos interessam ressaltar dessa abordagem que dialoga com a tensão permanente vivida por meninos em função dos vários processos de exclusão presentes em diferentes níveis e momentos da produção do futebol (FARIA, 2008).

\section{Aprendendo por entre as muitas práticas do futebol: um jogo de} muito contato entre seres humanos

A prática do futebol é de ampla difusão no Brasil e desenvolve-se em uma trama de complexas articulações. Em função disso, parece-nos interessante tomar a organização dessa prática como um caso emblemático, que visibiliza e nos permite indagar a respeito dos processos de aprendizagem, ou seja, para explorar essa trama e suas articulações para além do que elas nos informam acerca do específico do futebol.

Como afirmado, a abordagem da aprendizagem situada proposta por Lave (2001) foi-nos de grande valia para focalizar as práticas como instância de aprendizagem, em particular as noções de acesso às e de participação 
nas práticas. No entanto, os conceitos de comunidade de prática e participação periférica legitimada aparecem, nesse caso, desdobrados ou reorientados de forma singular. Em primeiro lugar, se o futebol pode ser considerado uma prática tradicional no Brasil, ou ainda, uma prática que possuiria contornos que nos levam a pensar no modelo do apprenticeship como apropriado para sua abordagem, ao mesmo tempo, ele está presente na sociedade em manifestações multifacetadas e contemporâneas, que inclui sua circulação na mídia e em aparatos tecnológicos como computadores e videogames: joga-se futebol em campo, como também assistese ao futebol intensamente pela TV, e joga-se futebol em videogames.

Em outras palavras, as diferentes formas de acesso à prática e da participação não nos permitem pensar em algo empiricamente circunscrito e de contornos muito bem definidos como uma comunidade de prática. Lave, em sua revisão a respeito do situated learning, já nos havia alertado para os problemas envolvidos nesse conceito, assim como no seu correlato de LPP - participação periférica legitimada - quando os três termos são tomados de forma dissociada 4 . Poderíamos afirmar, então, seguindo Lave, que o que permanece e reorienta o conceito é a noção de participação e a recorrência que essa participação pode alcançar em função das variadas formas de acesso às práticas. 0 que passamos a considerar então seria essa contínua exposição ao futebol - ou participação na prática futebolística - buscando registrar essa participação nos diferentes contextos onde ela se explicita, ou se dá a ver, para registrar o movimento dos praticantes, esse moto contínuo que produz a prática, ao mesmo tempo em que a prática produz os praticantes.

A partir desse enquadramento, a pesquisa intitulada inicialmente $O$ futebol dentro $e$ fora da escola: um estudo sobre as práticas de

4- A revisão dos conceitos fundamentais apresentados no livro Situated learning foi apresentada publicamente nas conferências realizadas em 2011 na UFMG (ver site IEAT/UFMG), e estão reorganizados em Lave (no prelo) - Access, participation and changing practice: the everyday life of learning. aprendizagem, desenvolvida na Faculdade de Educação entre 2004 e 2008 (FARIA, 2008) é aqui retomada como o fio condutor de uma narrativa que entrelaça a produção (aprendizagem) do futebol/futebolista e a produção (aprendizagem) da etnografia/etnógrafa. Não se trata de um percurso linear, nem fácil (como levam a crer as explicações correntes a respeito dos motivos da difusão do futebol no Brasil, isto é, o argumento de que o futebol é mais fácil do que os outros esportes). Trata-se de um percurso de aprendizagem que é, ao contrário, difícil e desafiador.

Para ambos os casos parecem oportunas as provocações de Lave (1993, p. 10), a respeito da aprendizagem como inerente ao engajamento nas práticas cotidianas:

[...] o que as pessoas estão aprendendo a fazer é um trabalho complexo e difícil. A aprendizagem não é um processo separado, nem um fim em si mesmo. Se ela parece sem esforço é porque em algum sentido ela é invisível.

As características do futebol (a sua produção cotidiana, a prática de ensino reduzida, a aprendizagem na prática, os diferentes níveis de participação, a não centralidade do discurso e os aspectos identitários envolvidos) impulsionaram a busca de abordagens capazes de lidar com o campo empírico. Como afırmamos, no Brasil, a prática do futebol é cotidiana e amplamente difundida. Não se circunscrevendo a espaços específicos e a formatos pré-definidos. Ela é de domínio público e se produz de múltiplas maneiras (futebóis) e em diferentes lugares, articula variadas formas de engajamento e conjuga diferentes gerações de praticantes. Para abordar a sua aprendizagem não se colocava como possibilidade, portanto, recortar um dos contextos da prática (eleito como o lugar onde a aprendizagem ocorre) para realizar a pesquisa de campo. Ainda que no país haja muitas situações em que o futebol possa estar associado a objetivos educacionais (quando ele é utilizado para disciplinar as 
crianças e jovens), a sua aprendizagem decorre da participação nos múltiplos contextos de prática a partir de diferentes engajamentos: jogar, assistir, conversar, ensaiar, torcer, ou, simplesmente, estar lá são modos de praticar futebol que redundam em aprendizagem da e na prática.

Respeitando essa característica (cuja articulação complexa ultrapassa os limites da prática em si e que não pode ser circunscrita a um dos contextos de sua produção), a pesquisa de campo, realizada em 2005, focalizou as práticas futebolísticas de jovens de um bairro da periferia da cidade de Belo Horizonte (MG). Esses jovens participavam do futebol na escola (nas aulas de educação física e no recreio); no campo de futebol do bairro (nas práticas de futebol do projeto Esporte esperança/segundo tempo, nos treinos do time juvenil e infantil, nos jogos de futebol amistosos e de campeonatos, nas práticas de lazer), na praça de esportes em frente à escola, em outros campos de futebol da cidade (jogos de futebol do campeonato amador).

0 objeto constituído implicava, pois, a escolha de um setting empírico em que os recursos para a aprendizagem do futebol viessem de várias fontes; em que fosse possível observar a ocorrência de intricada articulação da aprendizagem; em que o acesso e a participação na prática criassem um currículo potencial no sentido amplo; enfım, em que o futebol fizesse parte do cotidiano dos jovens.

A ampla trama de produção do futebol exigiu, desse modo, o cuidado de não simplificação da prática. Se em todos os contextos de prática era possível imediatamente identificar a ocorrência do futebol (denominação dada pelos sujeitos às diferentes formas de jogar), em cada um deles os praticantes experimentavam também singularidades. Esse inclusive era um aprendizado importante: jogar no futebol do recreio escolar era distinto do jogo de pelada no campo de futebol, por exemplo. Assim, se era possível observar que vários jovens praticavam futebol e se reencontravam em diferentes contextos, e que, a maioria das situações, era de jogo, algumas configurações da prática mudavam. Destacamos quatro:

a) No futebol do projeto social qualquer jovem/menino do bairro podia participar. Organizadas na forma de jogo, essas práticas tinham como singularidade a regência de um professor, a exigência da frequência escolar e, também, um conjunto de regras prescritas (que trazia implícita a sua lógica de prática educativa).

b) Nos campeonatos amadores da cidade e nos treinos dos times infantil e juvenil, a participação era regulada pelo gênero (sexo masculino), pela habilidade e pela faixa etária (12 a 17 anos). Selecionados nas práticas cotidianas do bairro, a participação nesses contextos articulava aprendizados distintos: aprender a jogar em determinada posição (especialização); incorporar as regras oficiais e as que regem a participação nesse contexto (disciplina, hábitos saudáveis). Mas, era apenas no campeonato que o praticante podia experimentar uma nova configuração da prática: a competição esportiva. Nela a principal lição era aprender a controlar as emoções e a relacionar com um jogo em que o resultado é definidor da exclusão e da permanência.

c) A diversidade de práticas e de modos de participar dos jogos tornava o campo de futebol do bairro um dos espaços centrais de produção do futebol no bairro e imediações. Frequentado principalmente por jovens do sexo masculino, no decorrer da semana, o campo era marcado por ampla rede de sociabilidade e comportava diferentes interesses.

d) $\mathrm{Na}$ escola, o futebol era prática cotidiana nas aulas de educação física e no recreio. Mas se o jogar bola era o modo de organização do futebol (pois não havia processos pedagógicos), havia duas diferenças entre participar do futebol nas aulas e no recreio: a primeira é em relação ao gênero, pois a aula era o único contexto em que as mulheres tinham a participação garantida; a segunda refere-se às diferenças etárias, pois a aula é o contexto escolar do futebol em que os praticantes são da mesma idade - não por causa 
de uma exigência do jogo, mas pelo formato organizacional da escola.

Enfım, no bairro a prática do futebol era intensa. Sem contemplar as práticas futebolísticas juvenis que ocorriam no âmbito da casa, os outros modos de participação e as práticas de futebol dos adultos (das quais os jovens participavam de forma indireta), os aspectos destacados acima revela uma ampla gama de possibilidades de participação/ aprendizagem dos jovens no futebol (contextos nos quais as mulheres tinham acesso restrito). É claro que a existência desse rol de possibilidades não significa homogeneidade de envolvimento e de investimento na participação, nem que todos tinham oportunidades iguais. As formas de exclusão, hierarquias e disputas referentes ao direito ao jogo eram parte do processo e a permanência na prática era, ao mesmo tempo, a iminência da possibilidade de aprender.

Em todos os contextos de produção do jogo havia a realização de peripécias com a bola. Complexas e repetidas à exaustão, essas práticas (pedaladas, dribles, passes, pênalti etc.) incorporavam mais do que técnicas. Um foco mais aprofundado mostrou também que outras aprendizagens estavam em questão nessas práticas. A atividade que segue narrada por Cadu (jovem de 17 anos) serve como exemplo para mostrar que o aprendizado do futebol incorporava aspectos diversos: a ética futebolística e a humildade como disposição corporal, por exemplo:

Igual o meu primo, meu primo tem, vai fazer 07 anos, se não me engano, ele começou a jogar bola com 4 anos, [...]. Ensino ele posicionamento pra chutar a bola, ensino ele a bater chutinho, [...] Brinco com ele, falo com ele a boleragem e tal, tipo assim, você tem [...], falo com ele, “- Tem que ser humilde, Douglas". Igual ele fica virando a cara assim [...], discriminando o outro jogador, aí o outro jogador pode apelar. Igual ele fica brincando assim e virando a cara, eu: “- Não Douglas, vamos ter humildade e tal”. (Cadu. Grifos nossos).
Praticando futebol em casa ou na rua, as indicações de Cadu ajudavam Douglas a constituir uma percepção do seu corpo/ movimento na relação com a bola e com o ambiente. Essas práticas cotidianas, que ocupavam importante parte da vida dos dois, permitiam que Douglas fosse constituindo a habilidade (INGOLD, 2000) sob a orientação de Cadu. Mais do que orientar Douglas na execução das técnicas futebolísticas, o que Cadu fazia era explicitar aspectos velados da prática social, a complexidade que envolve o jogo: a ética do futebol que requer do praticante senso de humildade incorporado (FARIA, 2008).

0 tipo de habilidade que Cadu queria que Douglas constituísse não é obtido por meio de informações escritas ou em formas convencionais de instrução. Disposto no próprio corpo do praticante era, pois, um conhecimento que exigia o envolvimento prático - que Douglas jamais encontraria fora da prática social. Cadu não criava, contudo, situações para ensinar a Douglas determinados aspectos do futebol. As orientações emergiam das interações na prática (FARIA, 2008).

Como foi possivel observar, em todas as práticas de futebol do bairro os modos de aprender se davam fundamentalmente nas relações entre pares (experientes e iniciantes) e nas oportunidades de participação na prática cotidiana. No bairro, "os recursos de estruturação para a aprendizagem" vinham de uma "variedade de fontes, não apenas da atividade pedagógica" (LAVE; WENGER, 1991, p. 94). Sendo assim, o envolvimento direto, contínuo e, por vezes, compulsivo dos jovens no futebol é que permitia que eles constituíssem a habilidade.

As várias citações do diário da pesquisa de campo (FARIA, 2008) servem para mostrar a natureza compartilhada da prática do futebol e que ele é incorporado na prática social por meio da experiência, ou seja, a corporeidade é amplamente engajada na aprendizagem do jogo. A complexidade que envolve a sua aprendizagem pode ser sintetizada na definição que Schiva (um praticante de 16 anos) faz do 
futebol: "O futebol é um jogo de contato; muito contato entre seres humanos e tem que treinar, porque se você não treinar, você não consegue jogar [...]” (FARIA, 2008).

A pesquisa de campo tornou possível acessar a prática futebolística como um diálogo silencioso e não como "uma articulação entre coisas fixas": como um "saber em andamento" como afirma Marchant (2010); ou como "presteza para ação" nas afırmações de Varela (1992). Ou ainda, como "pegar a moral do outro" - em que a ideia da ação se combina com elementos que qualificam a relação - ou seja, um tipo de percepção que distinguia o conhecedor/ habilidoso dos iniciantes, que tinham de pensar sobre como agir a cada situação. Na compreensão de Pelé - um praticante do jogo:

Não, nos primeiros [...] tem uns jogos aí que eu não estava fazendo gol, porque eu não estava acostumado com os meninos. Aí já tem outros jogos que eu já comecei a pegar a moral dos meninos. Aí isso aí é bom. Aí eu comecei a fazer muitos gols. [...] É, tem que aprender, aí você tem que olhar também as pessoas que você tá jogando pra você aprender como que ele joga, incentivar ele a jogar também, aí você vai pegando a moral do menino pra saber, aí você vai saber todos os toques que ele dá, aí você vai saber pegar. (FARIA, 2008, p. 168. Grifos nossos).

\section{A etnografia da aprendizagem e a exploração de possíveis articulações}

Provocados pela ideia de aprender vadiando e buscando focalizar contextos empíricos menos comumente associados ao tema da aprendizagem, e situações onde a aprendizagem é menos explorada - embora ela ocorra - dois outros trabalhos etnográficos do grupo multiplicaram as possibilidades de compreender o processo de aprender. Silva (2011) descreve como os meninos Xakriabá são inseridos muito cedo na participação das atividades da casa e da roça (situações em que eles sempre estão por perto quando adultos realizam atividades), e as diferentes gradações dessa participação. Como nas demais aldeias indígenas, também nas aldeias Xakriabá, os mundos de adultos e das crianças estão profundamente interligados (LOPES DA SILVA; MACED0; NUNES, 2002; TASSINARI, 2007).

Em função disso, as situações de aprendizagem ocorrem com delimitações muito marcadas quanto à atribuição de gênero ou tipo de desempenho exigido, e quase sempre em presença de modelos - dos adultos ou das demais crianças. A exploração atenta desse cenário - considerado como sendo de práticas tradicionais, em que a repetição dos padrões aparece como norma - levou-nos a verificar, ao contrário, que em toda repetição existe uma forte componente de criatividade e improvisação (INGOLD; HALLAM, 2007) .

No trabalho de Bergo (2011) a respeito das práticas cotidianas de participação de pessoas de diferentes idades em um terreiro de Umbanda, uma religião afro-brasileira, na periferia de Belo Horizonte, a pesquisadora também descreveu o caráter cotidiano da aprendizagem e o engajamento na prática como possibilidade do aprender no terreiro de Umbanda. No entanto, quando se trata da produção de umbandistas, o horizonte da aprendizagem não é referido somente a práticas específicas e circunscritas, mas envolve um conjunto maior de atividades e pressupostos que faz com que a participação nos momentos rituais, assim como na vida cotidiana do terreiro seja percebida como um todo a ser apreendido. Uma aprendizagem - como afirmam os próprios pais de santo - que não tem fim. Esse caráter de imersão totalizante - mas de forma distinta do que ocorre com o futebol, pois existem restrições bem delimitadas quanto às formas de participação - evidenciou outras

5- Discutimos em outra ocasião (GOMES et al., 2012) esses três contextos de investigação em relação a duas categorias de análise: 0 acesso às práticas (Cf. LAVE; WENGER, 1991) e a repetição das práticas (Cf. INGOLD, 2011). 
facetas, especialmente por se tratar de uma relação que ia além das fronteiras do humano e pautava as relações, e também as aprendizagens, para todos os agentes envolvidos, humanos e não humanos ${ }^{6}$.

É importante ressaltar que os dados das investigações acima referidos são resultados de uma construção com as muitas idas e vindas que compõem o exercício da etnografia. Do mesmo modo que o praticante hábil do futebol (uma vez tendo aprendido) não revela o seu esforço, também o relato etnográfico obscurece o esforço de aprendizado do etnógrafo. Assim, se as relações entre cultura e aprendizagem estavam na ordem do dia como alvo de interesse dessas pesquisas, aprender a etnografia era a outra face da experiência de campo - temática que segue em discussão.

Escapar das demarcações escolares, que evidenciam o aprender como o resultado de relações de ensino, de transmissão e internalização e, ao mesmo tempo, conseguir perceber a aprendizagem nas práticas cotidianas foi um dos desafios enfrentados no decorrer das investigações. 0 objeto definido pressupõe a necessidade de criação de novas possibilidades para acessar as práticas em campo. Afinal, para sujeitos escolarizados (e quase todos professores) era difícil ver aprendizagem fora das demarcações escolares e das práticas pedagógicas (a assimetria mestre aprendiz viciava o olhar).

Nos seus estudos a respeito da apprenticeship in critical ethnographic pratice, Lave (2011) convoca-nos a atentar para aspectos importantes que envolvem o fazer etnográfico. Problematizando as noções convencionais/ ocidentais de aprendizagem (como transmissão e internalização), a autora argumenta que essas noções não só não têm ajudado na constituição do acesso às práticas cotidianas, como, de fato, têm se apresentado como limitadoras dessa aproximação.

6- 0 tema da caça entre os meninos também traz a discussão dos diferentes agentes/atores que influenciam a caçada sobre/com os quais é preciso aprender (SILVA, 2011).
Há um mito a respeito do aprender que, historicamente, reduziu as descrições etnográficas da aprendizagem ao âmbito da escola. Agrupou-se, portanto, todas as práticas educacionais não escolares como socialização, como um processo único de formação (LAVE, 2011, p. 21-22). Assim, temos, de um lado, a aprendizagem formal associada à escolarização ocidental (é aquela que depende do ensino, conhecimento passível de ser transmitido) e, do outro, a noção de socialização associada à aprendizagem informal (que significa imitação; prática repetida; fazer irreflexivo e reprodução mecânica de rotinas).

A força desse modelo (invisível e/ou inconsciente para o pesquisador) incide também na forma de ver/analisar as práticas cotidianas. Dentre os efeitos problemáticos desse quadro podemos indicar a descomplexificação das práticas cotidianas e a reprodução de dicotomias tais como conhecimento científico x cotidiano, trabalho manual $\mathrm{x}$ trabalho mental, corpo $\mathrm{x}$ mente, natureza x cultura; e a produção de um tipo de texto etnográfico que revela muito mais a respeito do próprio pesquisador do que sobre a prática pesquisada (um tipo de narrativa etnográfica pela negação, ou seja, ao falar de tudo aquilo que os sujeitos não fazem, o pesquisador descreve as suas próprias noções e conceitos) ${ }^{7}$.

0 enquadramento teórico que impulsionou o estudo do aprendizado do futebol, da Umbanda e da circulação entre os meninos Xacriabá, dentre outros, nos permitiu pensar o percurso de investigação, também, como um processo de aprendizagem do fazer etnográfico (LAVE, 2011; HERZFELD, 2012). Um aprendizado, por certo, produzido na imersão cotidiana e na interseção entre prática etnográfica e prática teórica (HERZFELD, 2014): já que o etnógrafo não nasce antes da etnografia, mas se produz nela, tal qual os praticantes dos contextos investigados.

7- Ver a introdução de Lave (2011), e a necessária revisão das pesquisas precedentes como um processo de "mudança da prática teórica" (p. 35), quando aborda o tema da formação dos etnógrafos. Ver também a resenha de Herzfeld (2012) sobre o livro. 
Como afirma Velho (2006, p. 6), o antropólogo é duplamente aprendiz: “dos mestres acadêmicos, mas também dos seus mestres no campo". Velho (2006) ajuda-nos a compreender que o fazer etnográfico se produz no embate com as teorias, mas também no exercício cotidiano de imersão no contexto investigado. Ancorado nas colocações de Michael Herzfeld - que "fustigou a ideia antiga e perniciosa de que o conhecimento acadêmico não seja moldado por meios corporais" (VELHO, 2006, p. 9), o autor reitera a aproximação do métier do antropólogo e do métier do artesão.

Um exemplo interessante é a pesquisa de Wacquant (2002), cujo foco foi a aprendizagem do boxe. Aqui o interesse está no fato da aprendizagem de uma prática não ser um dispositivo complementar para outros temas mais relevantes em campo - e nesse sentido, poderíamos afirmar que ele assumiu integralmente a premissa de se tornar aprendiz dos mestres de campo ${ }^{8}$. Ao etnografar o boxe em um gueto norte americano no final dos anos 80, o caminho proposto foi o de se submeter ao próprio processo de aprender a prática pesquisada. Wacquant (2002) não apenas reitera a importância da imersão do pesquisador no campo; o pesquisador leva às últimas consequências a noção de observação participante e se lança como aprendiz de boxe em uma academia, assumindo a pesquisa como um experimento no próprio corpo.

Cabe, no entanto, ressaltar que o ofício do "antropólogo aprendiz" também possui limites. Como ajudam-nos a compreender Lave e Wenger (1991), o acesso às práticas cotidianas não é ilimitado. 0 conceito de participação periférica legitimada (LPP), cunhado pelos autores, permite entender que as diferentes práticas não estão disponíveis como possibilidade de participação/aprendizagem para todos e, ao contrário, que nelas também

8- 0 percurso etnográfico realizado por Wacquant não é um empreendimento solitário. Além dos já citados Learning capoeira, de Greg Downey (2005), e Trevor Marchant (2001) a respeito do ofício da carpintaria, em Marchand (2010, p. 8) vários dos autores usaram um apprentice-style method. se produzem praticantes legítimos/legitimados. Assim, o processo de aprender envolve o engajamento, mas o acesso não é algo que se coloca para todos - há exclusões. Esse aspecto colocou-se, por exemplo, logo de início na pesquisa de campo do futebol. Afınal, como poderia uma mulher/adulta participar/praticar das práticas masculinas de futebol de jovens se no Brasil o futebol se constitui como parte do exercício de certo modelo de masculinidade?

No Brasil, raramente uma mulher se torna praticante na rede de sociabilidade que o futebol constitui. Para a inserção no campo, foi preciso que a pesquisadora negociasse a presença em outros termos. Isso exigia considerar, permanentemente, o impacto da presença da pesquisadora/mulher no campo investigado - o que fazia do texto etnográfico o relato de uma relação (possível). Compreendida pelos praticantes do jogo como alguém que jamais poderia, de fato, conhecer o futebol (por dentro) o desafio foi fazer desse limite uma vantagem. Em campo, bastava informar o tema da pesquisa para que os praticantes homens - e os vários interlocutores com as quais a etnógrafa teve ocasião de interagir ao longo da pesquisa, em campo e na academia, e mesmo em sua vida social (inclusive suscitando polêmicas sobre $o$ fato de que ela não iria entender ou aprender nada se não agisse dessa ou daquela forma) - a convertessem imediatamente em aprendiz, com um enquadramento da relação que se instalava quase que naturalmente.

Qualquer que seja a forma de imersão no campo, o pesquisador terá de se haver com suas possibilidades e limites. 0 mais importante é colocar no horizonte da tarefa etnográfica que o que está em jogo é uma relação. No caso do futebol, os limites da presença feminina (por exemplo: jamais conseguir participar de um jogo; não conseguir acesso a determinados contextos, como o vestiário masculino; não passar despercebida em campo etc.) são descritos como reveladores de aspectos da prática futebolística que a imersão total (muitas vezes exibida pelos interlocutores homens que participaram ou 
dialogaram sobre a pesquisa) pode, por vezes ocultar. Portanto, o trabalho foi feito por alguém que, após ter vivido a experiência de pesquisa de campo (sem se confundir ou converter em nativo e sem passar pela experiência de produção do futebol no próprio corpo), pôde descrever aspectos que envolvem a prática.

0 caso do futebol, ao lado das demais pesquisas até aqui conduzidas, levou-nos a ampliar um horizonte de possibilidades dentro do qual é possível avançar propostas de etnografias das aprendizagens, horizonte que nos parece interessante delinear. Os aspectos sugeridos devem ser vistos não como um conjunto a ser considerado no todo, de uma só vez, mas como indicações que podem se articular em diferentes modos na configuração das práticas a serem investigadas. Seriam eles:

- práticas de amplo domínio público, muito difundidas, que nos permitem explorar as dinâmicas de sua produção em diferentes contextos (além do futebol, a dança e a música no Brasil; a improvisação jazzística nos EUA, dentre outras; como também a produção de imagens no mundo contemporâneo, com a profusão de instrumentos e tecnologias em diferentes níveis que se tornou muito difundida);

- práticas em cuja descrição e participação há uma centralidade do uso do corpo, permitindo visibilizar dinâmicas de como seriam, por exemplo, as da aprendizagem do movimento (INGOLD, 2011); ou nas palavras de Wacquant (apud VILLELA, 2002, p. 221), práticas que se situam "na fronteira do que é dizivel", e que exigem que "mergulhemos nel[a] como pessoa";

- práticas que envolvem uma particular destreza técnica, e que se apresentam em contextos específicos, como a pesca, a caça, a tecelagem e o grafismo sobre o corpo ou sobre os objetos, como realizado em comunidades indígenas; mas também destreza técnica no uso de equipamentos sofisticados do mundo contemporâneo, como computadores e outros equipamentos tecnológicos, ou ainda, a prática dos chamados esportes radicais que exigem grande destreza e preparação técnica;
- práticas cuja realização implica um compartilhamento de ações e percepções e que podem revelar essa articulação mais ampla da atividade de diferentes atores em interação com aparatos técnicos e tecnológicos.

Por fim, é importante reiterar que o conjunto dos estudos tem nos desafiado na busca de novas alternativas para lidar com o campo etnográfico. Noções convencionais acerca da aprendizagem, do social, do corpo (dentre outras) não são mais suficientes para lidar com o que emerge das relações entre o etnógrafo e os nativos (sejam futebolistas, umbandistas, Xakriabás etc.). Como nos convida Viveirosde-Castro (2002, p. 115) ao fazer a provocação: " 0 que acontece se recusarmos ao discurso do antropólogo sua vantagem estratégica sobre o discurso nativo?" A ideia de "levar a sério o que dizem os nativos" é um importante eixo das proposições contidas nesse ensaio programático, e é o que também nos mobiliza.

Nesse âmbito, a possibilidade de produção de teorias etnográficas, tal como apresentada por Goldman (2006), é hoje a perspectiva em andamento e ao mesmo tempo o desafio permanente que se coloca no nosso horizonte do trabalho. Usando a noção de experiência proposta por Lienhardt, no início dos anos 1960, Goldman (2006, p. 162) discute a "natureza da perspectiva antropológica a partir da relação entre saberes que os antropólogos criam e manuseiam e aqueles das pessoas com as quais trabalham". É para lidar com o impasse que se constitui no exercício etnográfico (interpretar o que dizem os nativos à luz dos conhecimentos do antropólogo, ou acreditar no que eles dizem), que Goldman (2006) propõe a noção de uma teoria etnográfica, ou a capacidade de imaginar uma relação entre diferentes enquanto diferentes: nem hierárquicas; nem igualitárias:

Uma teoria etnográfica não se confunde nem com a teoria nativa (sempre cheia de vida, mas por demais presa às vicissitudes cotidianas, às necessidades de justificar e racionalizar o mundo 
tal qual ele parece ser, sempre difícil de transplantar para outro contexto), nem como uma teoria científica (cuja imponência e alcance, ao menos na antropologia, só encontram paralelo em seu caráter anêmico e, em geral, pouco informativo). Evitando riscos do subjetivismo e da parcialidade, por um lado, do objetivismo e da arrogância por outro, trata-se de encontrar o que Milan Kundera (1991, p.78) chama de soberbo ponto mediano, o centro. Não o centro, ponto pusilânime que detesta extremos, mas o centro sólido que sustenta os dois extremos num notável equilíbrio (GOLDMAN, 2006, p. 170).
A proposição de se procurar identificar possíveis teorias etnográficas da aprendizagem - lembrando, porém, que o tema não necessariamente possa ser topicalizado pelos diferentes sujeitos em campo - parece-nos em sintonia com a indicação que nos faz Lave (2013) de descentrar da aprendizagem para focalizar as práticas e os praticantes. Como ela mesma já nos sugeriu, caberia aqui o exercício de pensar as questões que nos interessam em jejum dos termos conhecimento e aprendizagem (LAVE, no prelo) - o que pode ser um modo interessante de se aproximar daquilo que interessa aos nossos interlocutores, quando a eles nos dirigimos para entender o que e como aprendem.

\section{Referências}

ANDRÉ, Marli Eliza de. Etnografia da prática escolar. São Paulo: Papirus, 1995.

BERGO, Renata Silva. Quando o santo chama: 0 terreiro de umbanda como contexto de aprendizagem na prática. 2011. Tese (Doutorado em Educação) - Faculdade de Educação, Universidade Federal de Minas Gerais (UFMG), Belo Horizonte, 2011.

BERLINER, David; SARRÓ, Ramon (Eds.). Learning religion: anthropological approaches. New York: Berghahm Books, 2007.

BUENO, Belmira Oliveira. Entre a antropologia e a história: uma perspectiva para a etnografia educacional. Perspectiva, Florianópolis, v. 25, n. 2, p. 471-501, jul./dez. 2007.

COHN, Clarice. A criança indígena: a concepção Xikrin de infância e aprendizado. 2000. Dissertação (Mestrado em Antropologia) - Faculdade de Filosofia Letras e Ciência Humanas da Universidade de São Paulo, São Paulo, 2000.

DAUSTER, Tânia. Construindo pontes: a prática etnográfica e o campo da educação. In: DAYRELL, Juarez (Org.). Múltiplos olhares sobre educação e cultura. Belo Horizonte: UFMG, 1996.

DOWNEY, Greg. Learning capoeira: lessons in cunning from an afro-brazilian art. New York: Oxford University Press, 2005.

ERICKSON, Frederick; MOHATT, Gerald. Cultural organization of participation structures in two classrooms of Indian students. In: SPINDLER, George (Ed.). Doing the ethnography of schooling: educational anthropology in action. New York: Holt, Rinehart \& Winston, 1982. p. 132-174.

FARIA, Eliene. A aprendizagem da e na prática social: um estudo etnográfico sobre as práticas de aprendizagem do futebol em um bairro de Belo Horizonte. 2008. Tese (Doutorado em Educação) - Faculdade de Educação da Universidade Federal de Minas Gerais(UFMG), Belo Horizonte, 2008.

FARIA, Eliene. 0 esporte na cultura escolar: usos e significados. 2001. Dissertação (Mestrado em Educação) - Faculdade de Educação da Universidade Federal de Minas Gerais, Belo Horizonte, 2001. 
GOBBO, Francesca; GOMES Ana Maria. Etnografia nei contesti educativi. Roma: CISU, 2003.

GOLDMAN, Marcio. Alteridade e experiência: antropologia e teoria etnográfica. Etnográfica, Lisboa, v. 10, n. 1, p. 161-173, maio 2006.

GOMES, Ana Maria. Aprender a cultura. In: LOUREIRO, Maria Helena Mourão; FIGUEIREDO, Betânia Gonçalves. Cultura e educação: parceria que faz história. Belo Horizonte: Mazza: Instituto Cultural Flávio Gutierrez, 2006.

GOMES, Ana Maria. Um (possível) campo de pesquisa: aprender a cultura. In: TOSTA, Sandra Pereira; ROCHA, Gilmar (Orgs.). Diálogos sem fronteira: história, etnografia e educação em culturas ibero-americanas. Belo Horizonte: Autentica, 2014.

GOMES, Ana Maria et al. Learning [the] culture In Brazil among soccer players and traditional groups. AAA ANNUAL MEETING, 111. Anthropologists explore learning: crossing cultural and temporal borders, San Francisco, nov. 2012. Anais... San Francisco: [s. n.], 2012.

GREEN, Judith L.; DIXON, Carl N.; ZAHARLICK, Amy. A etnografia como uma lógica de investigação. Tradução de Adail Sebastião Rodrigues Júnior e Maria Lúcia Castanheira. Educação em Revista, Belo Horizonte, v. 42. p. 13-79, 2005.

HEATH, Shirley Brice. Ways with words: language, life, and work in communities and classrooms. Cambridg: Cambridge University Press, 1983.

HERZFELD, Michael. Apprenticeship in critical ethnographic practice, book review. American Anthropologist, v. 114, n. 4, p. 707-708, dec. 2012.

HERZFELD, Michael. Antropologia prática teórica na cultura e na sociedade. Petrópolis: Vozes, 2014.

INGOLD, Tim. The perception of the environment: essays on livelihood, dwelling and skill. New York: Routledge, 2000.

LAVE, Jean. Apprenticeship in critical ethnographic practice. Chicago: University of Chicago Press, 2011.

LAVE, Jean. Learning in/as practice. Belo Horizonte. UFMG, no prelo.

LAVE, Jean. Situated Learning in a long term perspective. Conferência oral. Programa de pós-graduação da Faculdade de Educação da Universidade Federal de Minas Gerais, UFMG, 2013.

LAVE, Jean. The practice of learning. In: CHAIKLIN, Seth; LAVE, Jean. Understanding practice: perspectives on activity and context. Cambridge: Cambridge University Press, 1993.

LAVE, Jean; WENGER, Etienne. Situated learning: legitimate peripheral participation. Cambridge: Cambridge University Press, 1991.

LOPES DA SILVA, Aracy (Org.). Antropologia, história e educação. São Paulo: Global, 2001.

LOPES DA SILVA, Aracy; MACEDO, Ana da Silva; NUNES, Ângela (Orgs.). Crianças indígenas, ensaios antropológicos. São Paulo: Mari: Fapesp: Global, 2002.

MARCHAND, Trevor. Making knowledge: explorations of the indissoluble relation between minds, bodies, and environment. Journal of the Royal Anthropological Institute, London, v. 16, Issue Supplement, S1-S21, 2010.

MARCHAND, Trevor. Minaret building \& apprenticeship in Yemen. New York, Routledge, 2001.

MEHAN, Hugh. Learning lessons: social organization in the classroom. Cambridge: Harvard University Press, 1979.

OLIVEIRA, Amurabi. Por que uma etnografia em sentido estrito e não estudos etnográficos em educação? Educação e Contemporaneidade, Salvador, v. 22, n. 40, p. 69-81, jul./dez. 2013.

PEIRANO, Mariza. A favor da etnografia. Anuário Antropológico, Brasília, DF, n. 130, p. 197-223, 1992.

PHILLIPS, Susan. Invisible culture: communication in classroom and community on the Warm Springs Indians reservation. Prospects Heights. llinois: Waveland Press, 1993.

ROCKWELL, Elsie (Org.). La escuela cotidiana. México: Fondo de Cultura Económica, 1995. 
ROCKWELL, Elsie. Recovering history in the study of schooling: from the longue durée to everyday co-construction. Human Development, v. 42, n. 3, p. 113-128, 1999.

SILVA, Rogério Correia da. Circulando com os meninos: infância, participação e aprendizagens de meninos indígenas Xacriabá. 2011. Tese (Doutorado em Educação) - Faculdade de Educação da Universidade Federal de Minas Gerais (UFMG), Belo Horizonte, 2011.

TASSINARI, Antonella. Concepções Indígenas de Infância no Brasil. Revista Tellus, Campo Grande, v. 7, n. 13, p.11-25, out. 2007.

TASSINARI, Antonella. Múltiplas infâncias: o que a criança indígena pode ensinar para quem já foi à escola ou a sociedade contra a escola. In: ENCONTRO ANUAL DA ANPOCS, 33., Caxambu. Anais..., Caxambu: ANPOCS, 2009. ANP0CS - GT16, out. 2009.

VARELA, Francisco. Sobre a competência ética. Tradução de Artur Mourão. Lisboa: Edições 70, 1992.

VELHO, Otávio. Trabalhos de campo: antinomias e estradas de ferro. Rio de Janeiro: UERJ, 2006. Aula inaugural no Instituto de Filosofia e Ciências Humanas da Universidade do Estado do Rio de Janeiro, mar. 2006.

VILLELA, Jorge Mattar. Corpo e alma: notas etnográficas de um aprendiz de boxe. Mana, Rio de Janeiro, v. 8, n. 2, p. 220-222, out. 2002.

VINCENT, Guy; LAHIRE, Bernard; THIN, Daniel. Sobre a história e teoria da forma escolar. Educação em Revista, Belo Horizonte, n. 33, p. 7-48, jun. 2001.

VIVEIROS-DE-CASTRO, Eduardo. 0 nativo relativo. Mana, Rio de Janeiro, v. 8, n. 1, p. 113-148, 2002.

WACQUANT, Loïc. Corpo e alma: notas etnográficas de um aprendiz de boxe. Rio de Janeiro: Relume Dumará, 2002.

WAGNER, Roy. A invenção da cultura. São Paulo: Cosac\&Naif, 2010.

WILLIS, Paul. Learning to labor: how working class kids get working class jobs. New York: Columbia University Press, 1977.

WOODS, Peter. Inside schools: ethnography in educational research. London: Routledge, 1986.

Recebido em: 15.01.2015

Aprovado em: 26.03.2015

Ana Maria Rabelo Gomes é professora associada e membro do PPGE-Inclusão Social na Faculdade de Educação da UFMG. Coordena o Observatório da Educação Escolar Indígena (OEEI/UFMG) e o Grupo de Pesquisa em Antropologia \& Educação na FaE/UFMG.

Eliene Lopes Faria é professora do colégio técnico da UFMG. Doutora em educação pela FaE/ UFMG. Professora do mestrado profissional educação e docência da FaE/ UFMG e é membro do Grupo de Pesquisa Antropologia \& Educação da mesma faculdade. 